\title{
The intellectual and moral integrity of bioethics: response to commentaries on "A case study in unethical transgressive bioethics: 'Letter of concern from bioethicists' about the prenatal administration of dexamethasone".
}

Laurence B McCullough

Baylor College of Medicine

Frank A Chervenak

Weill Medical College of Cornell University

Robert L Brent

Thomas Jefferson University and Alfred I. duPont Hospital for Children

Eollow this and additional works at: https://jdc.jefferson.edu/pedsfp

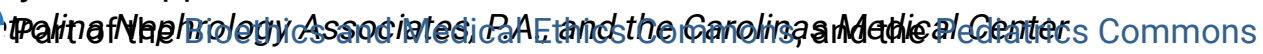

Let us know how access to this document benefits you

\section{Recommended Citation}

McCullough, Laurence B; Chervenak, Frank A; Brent, Robert L; and Hippen, Benjamin, "The intellectual and moral integrity of bioethics: response to commentaries on "A case study in unethical transgressive bioethics: 'Letter of concern from bioethicists' about the prenatal administration of dexamethasone"." (2010). Department of Pediatrics Faculty Papers. Paper 30. https://jdc.jefferson.edu/pedsfp/30

This Article is brought to you for free and open access by the Jefferson Digital Commons. The Jefferson Digital Commons is a service of Thomas Jefferson University's Center for Teaching and Learning (CTL). The Commons is a showcase for Jefferson books and journals, peer-reviewed scholarly publications, unique historical collections from the University archives, and teaching tools. The Jefferson Digital Commons allows researchers and interested readers anywhere in the world to learn about and keep up to date with Jefferson scholarship. This article has been accepted for inclusion in Department of Pediatrics Faculty Papers by an authorized administrator of the Jefferson Digital Commons. For more information, please contact: JeffersonDigitalCommons@jefferson.edu. 


\section{As submitted to \\ The American Journal of Bioethics}

And later published as:

The Intellectual and Moral Integrity of

Bioethics: Response to Commentaries

on "A Case Study in Unethical

Transgressive Bioethics: 'Letter of

Concern from Bioethicists' About the

Prenatal Administration of

Dexamethasone"

\section{Volume 10, Issue 9:W3-W5, September 2010 DOI: $10.1080 / 15265161.2010 .505143$}

Laurence B. McCullough, Baylor College of Medicine

Frank A. Chervenak, Weill Medical College of Cornell University

Robert L. Brent, Thomas Jefferson University and Alfred I. duPont Hospital for Children

Benjamin Hippen, Metrolina Nephrology Associates, P.A., and the Carolinas Medical Center

In our target article we showed that the Letter of Concern (LoC) fails to meet accepted standards for presenting empirical data for the purpose of supplementing a normative claim and for argument-based normative ethics. The LoC fails to meet the standards of evidence-based reasoning by making false claims, failing to reference data that undermine its key premises, and misrepresenting and misinterpreting the scientific publications it selectively references. The LoC fails to meet the standards of argument-based reasoning by treating as settled matters what are, instead, ongoing controversies, offering "mere opinion" as a substitute for argument, and making contradictory claims. The LOC is methodologically defective and thus a case study in unethical transgressive bioethics. Not 
withdrawing the LoC will damage the field of bioethics, making this case study in unethical transgressive bioethics important for the entire field.

\section{MEETING THE STANDARDS OF EVIDENCE-BASED AND ARGUMENT-BASED REASONING IN BIOETHICS}

We deliberately refrained from addressing normative concerns regarding whether dexamethasone ought to be recommended for use in gravid women at risk for transmitting CAH to a child. Most of the commentators (Dolan 2010; Green 2010; Kamenova 2010; Reis and Kessler 2010; Robichaud 2010; Tamar-Mattis 2010) take us to task for giving short shrift to this. Whatever ancillary merits their arguments have, they miss the point: It is neither necessary nor sufficient to hold any particular view regarding the normative advisability of recommending dexamethasone in this clinical context, in order to insist that thosewhoadvance any particular normative view of the matter have an obligation, as amatter of intellectual and moral integrity in bioethics, to meet the standards of evidence-based and argument-based reasoning.

Kraft (2010) takes the view that "bioethical reflection requires the interrogation of practices that appear problematic" (emphasis added). This is an invitation to anarchy when "appearances" fail to correspond to facts in plain view. Dreger, Feder, and Lindemann (2010) dismiss the requirement of evidence-based reasoning as "weird logic." If hewing to the "right" normative ends is sufficient grounds for exempting scholars from adherence to accepted standards of intellectual and moral integrity, then both scientific and normative inquiry are gravely damaged. If this egregiously defective methodology is accepted in bioethics, the field shall be, justly, consigned to History's dustbin as mere politics by other means.

It is therefore scandalous to find that only Lantos (2010) addresses any of the series of empirical missteps found in the LoC. No other commentator thinks it ethically important enough to emphasize that all the pertinent empirical data on the effects of dexamethasone on fetal phenotypic and cognitive development, or on gravid women, should be accurately presented before publicly issuing a j'accuse. They endorse the ethical permissibility of falsely insinuating that a prominent researcher willfully and systematically ignored these considerations. One would never know, from the LoC, or these commentaries, that Dr. New's research for the last two decades has focused precisely on the study of the long-term outcomes of this therapy for gravid women and their children and has had IRB approval. Instead, our criticism is characterized as a gratuitous and 
spectacular display (at best), as illicit "monitoring"or "silencing," or (at worst) as a surreptitious attempt to deflect regulatory attention. It is staggering that many of the commentators believe that Dr. New need not fear the repercussions of damaging and widely promulgated accusations-the worst possible interpretation of her motives rearranged as tendentious rhetorical questions 1 -and an aggressive invitation to regulatory scrutiny, unless she somehow has something to hide. This is Salem's justice. The collateral damage already done to Dr. New's reputation is derived from an illicitly borrowed presumption of scholarly due diligence on the part of her critics. When this presumption is abused, as it is in the LoC, it is more than her critics who suffer. It is the intellectual and moral integrity of bioethics itself.

Only Lantos seems to recognize our original point, that a randomized, prospective clinical trial (which no one, including Dr. New, fails to endorse as a methodological ideal), in the case of a disease with a very low incidence and prevalence, is so statistically underpowered as to be meaningless or, worse, materially misleading. The European PREDEX study represents the moral and methodological ideal insisted upon in the LoC. However, it has been able to enroll so few subjects that its data have been so riddled with Type I errors that it has not been able to reproduce previously reported findings. This creates a dilemma for the LoC and for Dreger, Feder, and Lindemann. On the one hand, affirming PREDEX as the sole means of ascertaining the safety of administering dexamethasone in this context would eliminate the likelihood of any empirically meaningful research on the matter (given the inevitably small sample size and thus low statistical power). This is methodologically disingenuous. On the other hand, such an affirmation admits that pregnant women and fetuses would be exposed to acceptable risks. But this is just what the LoC denies, making the call for clinical trials in the LoC and by Dreger, Feder, and Lindemann ethically disingenuous. The insistence on a randomized, prospective controlled trial is proffered in bad faith.

\section{THE BIOETHICS IMAGINARY}

We find only a few points of disagreement with Reis and Kessler's summation of the historical context of the tragic record of the crudemedicalization of intersex conditions by John Money, except to observe that (a) Money's approach has been discredited philosophically (McCullough 2002) and no longer shapes current standards in pediatric endocrinology (Lee, Houk, Ahmed, and Hughes 2006), (b) Dr. New is not Dr. Money, and (c) Reis and Kessler's narrative is wholly irrelevant to whether one is obliged to get one's facts right. Still, they and Green and Tamar-Mattis repeat the charge, more crudely leveled by Dreger, Feder, 
and Lindemann, that the normative impetus for using dexamethasone here could only be predicated on the heterosexist and homophobic premise that dexamethasone somehow prevents lesbianism.

Neither Dreger, Feder, and Lindemann, nor Green, nor Reis and Kessler, nor Tamar-Mattis offers any evidence whatever for this accusation that investigators of prenatal administration of dexamethasone are engaging in heteronormative eugenics. 2 Having exempted bioethics from the discipline of evidence-based reasoning, Dreger, Feder, and Lindemann expect their readers and the readers of the LoC to accept their repeated trope of heart-felt "concern," expressed more in sorrow than anger, as an intellectually and morally authoritative substitute. They also expect two government agencies and three universities, all committed to the improvement of medicine by evidence-based reasoning and bioethical oversight, to accept that evidence-based reasoning is "weird logic" and thus not required in research ethics. They thereby introduce into bioethics what we call the bioethics imaginary2: the systematic violation of evidence-based reasoning posing as methodologically legitimate.

In the hands of Dreger, Feder, and Lindemann and their fellow interrogators the bioethics imaginary and its menagerie of "appearances" come to a bad end. Dreger, Feder, and Lindemann, along with Reis and Kessler, style themselves champions of the autonomy of pregnant women. It is therefore at least ironic that their deployment of the bioethics imaginary completely undermines the autonomy of pregnant women. Reis and Kessler imply that all these women seek to have, or would permit having, supplicant-like, their pregnancies and their choices for their children routinely abrogated by physicians, thus endorsing an unwarranted, paternalist condescension toward the considered views and capacity for autonomous judgment of pregnant women. It "appears" to Dreger, Feder, and Lindemann that clinically experienced, licensed physicians prescribing dexamethasone would blithely permit Dr. New to "push ... all of the risk onto obstetricians who may have had no idea what they were part of and none of the expertise required to inform patients of the risks and unknowns." Dreger, Feder, and Lindemann thus treat pregnant women as children, as heteronomous creatures helplessly susceptible to manipulation by physicians (supported by professional organizations, peer reviewers, and editors of professional journals of endocrinology and sexuality), all of whom may have become the genial puppets of Dr. New, and thus incompetent, professionally illiterate, and criminally stupid. 
Fully liberated from accepted standards of evidence-based and argument-based reasoning, the LoC and Dreger, Feder, and Lindemann expect their readers to embrace the trope of heartfelt, ideologically selfratifying "concern," littered with groundless innuendos, as intellectually and morally acceptable in bioethics. We cordially decline to do so, based on the belief that, as a precedent, this would be catastrophic for the moral and intellectual integrity of the field of bioethics. We are not at all confident about whether subsequent events will affirm or undermine this integrity. We renew our call for the LoC to be withdrawn and for cosignatories to remove their names from it. 3 The LoC, its signatories, and its defenders in the commentaries damage the rights and interests of persons with disorders of sexual development, which are best served by evidence-based and argument-based bioethics guiding rigorous scientific and clinical investigation.

1. Dreger, Feder, and Lindemann repeatedly commit the methodological error of substituting rhetorical questions for evidencebased and argumentbased reasoning. Consider two examples. They ask, "Are they-New and other clinicians-really thinking that it's a good idea to use prenatal dex because otherwise girls are more likely to end up tomboyish, aggressive, and lesbian?" Philosophers will note in passing the loaded question fallacy ("So, when did you stop beating your husband?"). This is not only a crude reductio of a vast array of clinical and normative concerns; it also requires that the signators of the LoC both affirm and deny that the use of fetal dexamethasone is only for cosmetic purposes, yet another violation of the principle of noncontradiction. They also ask, "McCullough and colleagues reveal to us New's apparent excuse for not having IRB approval: She actually wrote only one script for prenatal dex. So why does theMaria New Children's Hormone Foundation boast to prospective patients that 'She has treated over 600 pregnant women at risk for the birth of a CAHaffected child'?" The context of the text on the foundation's webpage is plain: Treatment is offered under the protocol we described, under which Dr. New does not prescribe dexamethasone to the patients of referring physicians.

2. The phrases "transgressive bioethics" and "heteronormative eugenics" were coined by Dr. Hippen and therefore would not appear in any available literature search, as Kraft discovered concerning the former. The phrase "the bioethics imaginary" originates with Dr. McCullough. We hope these phrases, on balance, are more illustrative than obscurantist of the rhetorical maneuvers used in the LoC and by Dreger, Feder, and Lindemann and other commentators, but concede the risk of the reverse with any neologism. 
3. Dreger, Feder, and Lindemann (2010) come to the defense of the LoC. Feder was the corresponding author (fetaldex.org 2010a). Lindemann solicited co-signatories to the draft version of the LoC (mcw bioethics listserv e-mail posted January 29, 2010, 11:48 a.m.), and Feder and Dreger jointly sent letters that followed on the submission of the LoC to the Department of Health and Human Services (DHHS), Food and Drug Administration (FDA), and three universities (fetaldex.org 2010b). Dreger, Feder, and Lindemann therefore bear direct responsibility forwithdrawing the LoC. As the person publicly taking responsibility for posting on fetaldex.org, Dreger bears direct responsibility for posting on fetaldex.org the announcements of the withdrawal of the LoC and of withdrawals of co-signatories.

\section{REFERENCES}

Dolan, T. 2010. Quo OHRP?: Faithful arbiter or pro wrestling ref? American Journal of Bioethics 10(9): 53-55.

Dreger, A., E. K. Feder, and H. Lindemann. 2010. Still concerned. American Journal of Bioethics 10(9): 46-47

fetaldex.org. 2010a. Letter of concern of bioethicists. Available at: (accessed June 9, 2010).

fetaldex.org. 2010b. Follow up letter to institutions originally contacted. Available at: (accessed June 9, 2010).

Green, J. 2010. The view from the inside: More confusion (and coziness) than consent. American Journal of Bioethics 10(9): 60-61.

Kamenova, K. 2010. Politics and persuasion in medical controversies. American Journal of Bioethics 10(9): 69-70.

Kraft, R. E. 2010. Why I signed, and why I would do it again. American Journal of Bioethics 10(9): 62.

Lantos, J. 2010. On cultural sanctions for shaping our children's genitalia. American Journal of Bioethics 10(9): 56-57.

Lee, P. A., C. P. Houk, S. F. Ahmed, and I. A. Hughes, International Consensus Conference on Intersex organized by the Lawson Wilkins Pediatric Endocrine Society and the European Society for Paediatric Endocrinology. 2006. Consensus statement on the 
management of intersex disorders: International Consensus Conference on Intersex. Pediatrics 118(2): e488-e500.

McCullough, L. B. 2002. A framework for the ethically justified management of intersex conditions. Advances in Experimental Medicine and Biology 51 1: 149-165; discussion 165-173.

Reis, E., and S. Kessler. 2010. Why history matters: Fetal dex and intersex. American Journal of Bioethics 10 (9): 58-59.

Robichaud, A. 2010. Attracting attention: Right or wrong. American Journal of Bioethics 10(9): 67-68.

Tamar-Mattis, A. 2010. An attempt to shut down discourse about a controversial practice will not benefit patients, human subjects, the bioethics community, or the research community. American Journal of Bioethics 10(9): 63-65. 